\title{
ЛОПАРИТ АЛЛУАЙВСКОГО УЧАСТКА ЛОВОЗЕРСКОГО ЭВДИАЛИТОВОГО МЕСТОРОЖДЕНИЯ
}

\section{Михайлова Ю.А., Малыгина А.В., Пахомовский Я.А., Базай А.В., Калашников А.О.}

Геологический институт КНЦРАН, Anamumb, alexaeule@yandex.ru

Второй по размерам после Хибинского, девонский Ловозерский щелочной массив расположен в западной части Кольского полуострова, среди метаморфических комплексов КольскоНорвежского мегаблока. Наиболее характерными его чертами являются чёткая расслоенность, огромное количество послойных ксенолитов слабопереработанных оливиновых базальтов, туфов и туффитов ловозерской свиты и наличие крупнейших месторождений $\mathrm{Ti}, \mathrm{Nb}, \mathrm{Ta}, \mathrm{REE}$ и $\mathrm{Zr}[1,2]$.

Массив сложен субгоризонтальными (падение к центру массива под углами до $10^{\circ}$ ) ритмично чередующимися слоями нефелиновых сиенитов фойяит-малиньит-шонкинитового ряда и

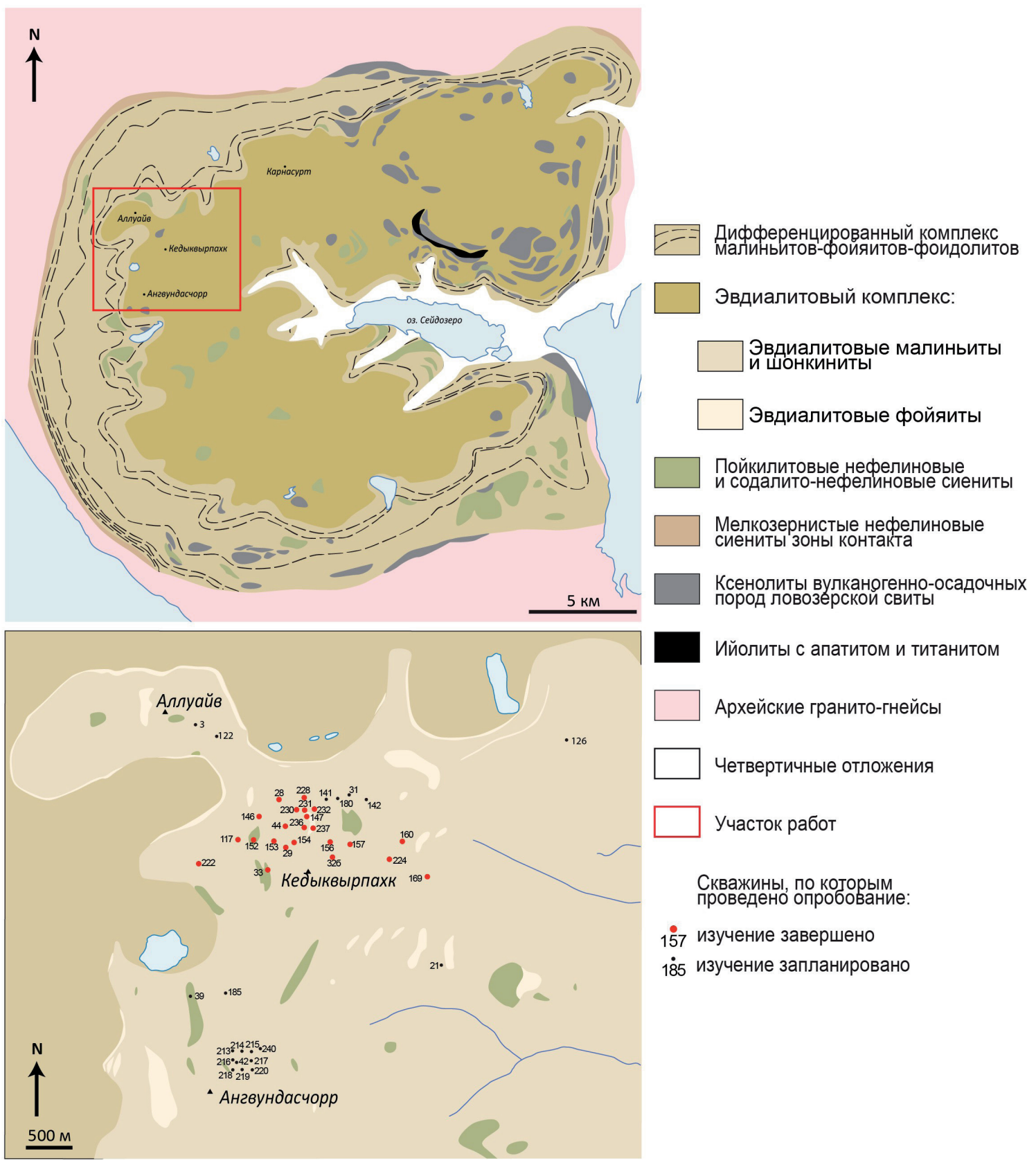

Рис. 1. Схема геологического строения Ловозёрского щелочного массива (по [1] с дополнениями [3]) и Аллуайвского участка Ловозёрского эвдиалитового месторождения [2]. 
мельтейгит-уртитов. Его нижняя часть представлена дифференцированным комплексом (мощностью более 2 км) из более чем 7 ритмично чередующихся пачек пород, в которых от подошвы к кровле постепенно нарастает содержание микроклин-пертита, щелочных амфиболов и клинопироксенов с соответствующим переходом от уртитов к ийолитам, затем к фойяитам и малиньитам. На контакте между соседними слоями располагаются тонкие (до 50 см) прослои лопаритсодержащих малиньитовшонкинитов (со стороны подстилающих нефелиновых сиенитов) - ийолитов-мельтейгитов (со стороны покрывающих фоидолитов) [3].

Эвдиалитовый комплекс мощностью 100-800 м включает линзы тех же самых пород, что и дифференцированный комплекс, но он сравнительно слабо дифференцирован и существенно обогащён эвдиалитом (до 80 об. \%) [1-4]. Хотя эвдиалитсодержащие породы обычно обеднены лопаритом $[2,3]$, развитые среди них отдельные линзы нефелиновых сиенитов и фоидолитов с низким содержанием эвдиалита включают в себя лопарит в количестве $0.5-1$ об. \%. Это позволяет рассматривать Эвдиалитовый комплекс в качестве сверхкрупного Zr-REE-Ti-Nb-Ta месторождения, наиболее перспективными в пределах которого являются Аллуайвский (см. рис. 1) и Чивруайский участки [3].

В пределах Ловозерского массива был детально изучен Аллуайвский участок. Он сложен эвдиалитовыми малиньитами, резко доминирующими над другими разновидностями пород (63 \%). Среди малиньитов располагается протяжённый пласт фойяитов (18 \% от всего объема пород) мощностью до 100 м. Шонкиниты и фоидолиты (8 \% и 10 \% соответственно) слагают разрозненные послойные линзы в толще малиньитов.

В пределах Аллуайвского участка лопарит встречается повсеместно, хотя его содержание варьирует от единичных мельчайших (до 5 мкм) включений в породообразующих минералах до 3 об.\% [2]. Лопарит - $(\mathrm{Na}, \mathrm{REE}, \mathrm{Ca}, \mathrm{Sr}, \mathrm{Th})(\mathrm{Ti}, \mathrm{Nb}) \mathrm{O}_{3}$ - сложный редкоземельный титано-ниобат из группы перовскита [6]. Благодаря широко проявленным изоморфным замещениям, лопарит и другие представители этой группы являются чувствительными индикаторами условий минералообразования, что позволяет использовать их в качестве типоморфных минералов [7].

\section{Методика исследования}

Для выявления закономерностей изменения состава лопарита в пределах Ловозёрского эвдиалитового месторождения использовался метод трёхмерного минералогического картирования, ранее опробованный на Ковдорском месторождении магнетита, апатита и бадделеита [5]. Сначала был произведен отбор координатно-привязанных образцов (через 5 м) из керна скважин, пробуренных в пределах Аллуайвского участка (см. рис. 1), и изготовлены комбинированные шлифы. Их изучение проводилось при помощи оптического и электронного микроскопов (Leo-1450 c EDSанализатором Quantax). Затем был проведен волнодисперсионный микрозондовый анализ состава лопарита в 198 образцах при помощи электроннозондового микроанализатора Cameca MS-46. Факторный анализ содержания оксидов в массовых процентах произведён методом главных компонент с варимаксным вращением в программе Statistica-8. Закономерности изменения состава минерала в пространстве анализировались по трёхмерной минералогической модели Аллуайвского участка, построенной при помощи программного комплекса Micromine-16.

\section{Результаты}

После обработки данных микрозондового анализа выяснилось, что кроме собственно лопарита в выборку попали и другие минералы группы перовскита - луешит, перовскит, таусонит (табл. 1). Однако их доля от общего количества анализов невелика - около 35 анализов. Результаты факторного анализа содержаний оксидов в массовых процентах представлены в таблице 2 и на рисунке 2. Первый фактор выявил основную схему изоморфных замещений: $0.5 \mathrm{Na}^{+}+0.5 R E E^{3+}+\mathrm{Ca}^{2+}+2 \mathrm{Ti}^{4+} \leftrightarrow$ $2 \mathrm{Na}^{+}+2(\mathrm{Nb}, \mathrm{Ta})^{5+}-$ т. е. «лопарит + перовскит $\leftrightarrow$ луешит», которая обусловливает отрицательную корреляцию между $\mathrm{Nb}+\mathrm{Ta}$ и REE+Ti (табл. 1). В большинстве образцов малиньитов и шонкинитов рассматриваемый минерал обогащён Zr и REE, - при этом, часть образцов малиньитов содержит в своем 


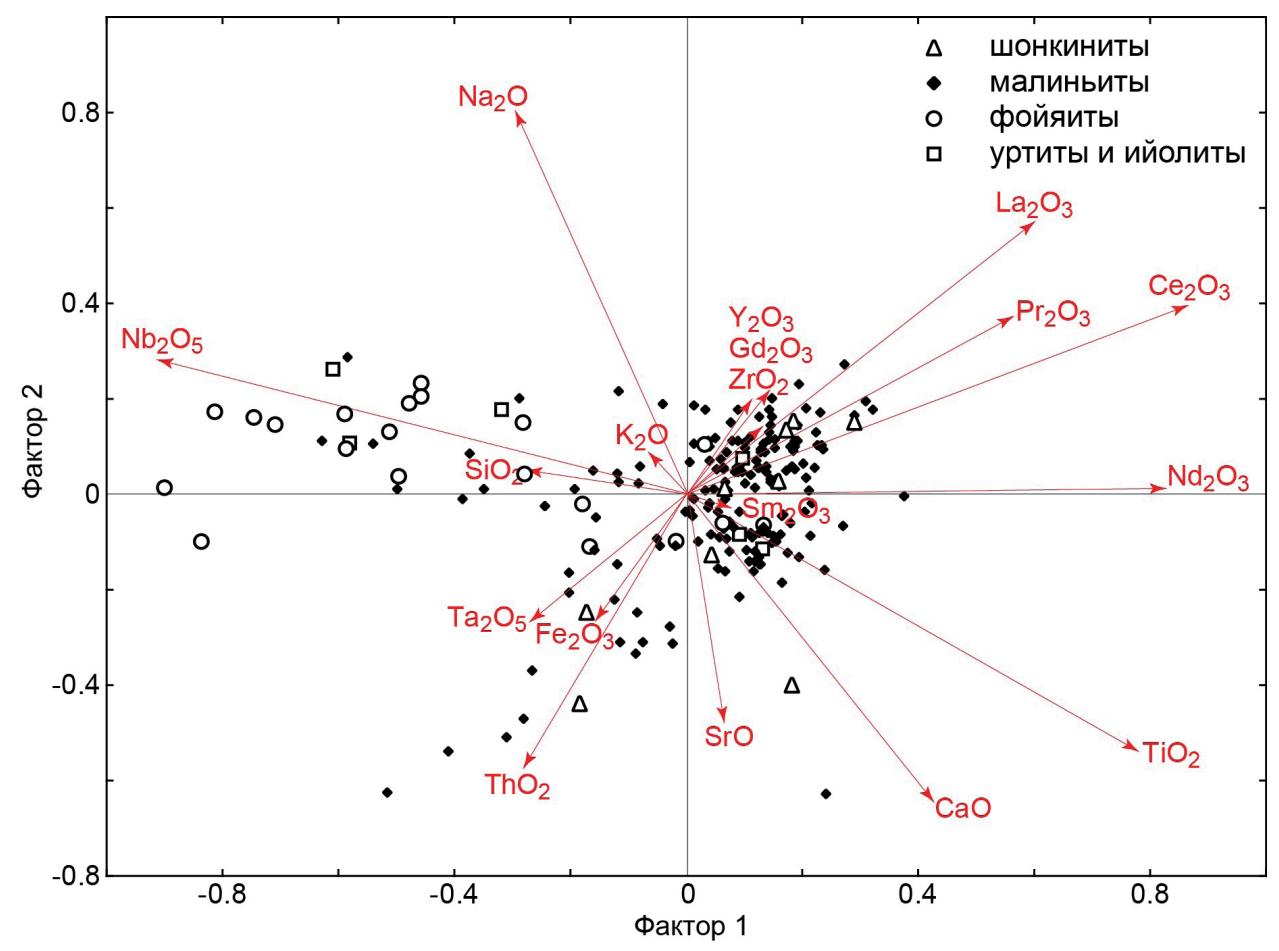

Рис. 2. Результаты факторного анализа данных о составе лопарита.

Длины векторов-переменных и векторов-объектов не согласованы.

составе лопарит с повышенным содержанием тория, тантала и железа. Вместе с тем, лопариты малиньитов образуют компактное поле точек, что означает отсутствие каких-либо значительных флуктуаций в составе лопарита этих пород. В фойяитах и уртитах лопарит характеризуется повышенным содержанием $\mathrm{Nb}$ вплоть до перехода в луешит (рис. 2).

Таблица 1. Данные о химическом составе лопарита (мас. \%).

\begin{tabular}{|c|c|c|c|}
\hline Компонент & $\frac{\text { медиана } \pm \text { станд. откл. }}{\text { min-max }}$ & Компонент & $\frac{\text { медиана } \pm \text { станд. откл. }}{\min -\max }$ \\
\hline $\mathrm{SiO}_{2}$ & $\frac{0.64 \pm 0.98}{0.08-4.6}$ & $\mathrm{~K}_{2} \mathrm{O}$ & $\frac{0.12 \pm 0.11}{0-1.06}$ \\
\hline $\mathrm{TiO}_{2}$ & $\frac{38.27 \pm 5.37}{20.13-51.4}$ & $\mathrm{Nb}_{2} \mathrm{O}_{5}$ & $\frac{15.42 \pm 8.98}{6.88-50.12}$ \\
\hline $\mathrm{ZrO}_{2}$ & $\frac{0.32 \pm 0.15}{0-0.46}$ & $\mathrm{Y}_{2} \mathrm{O}_{3}$ & $\frac{0.18 \pm 0.1}{0.03-0.3}$ \\
\hline $\mathrm{Al}_{2} \mathrm{O}_{3}$ & $\frac{0.23 \pm 0.4}{0.02-1.53}$ & $\mathrm{La}_{2} \mathrm{O}_{3}$ & $\frac{7.95 \pm 1.53}{1.59-10.12}$ \\
\hline $\mathrm{FeO}$ & $\frac{0.31 \pm 0.5}{0-5.82}$ & $\mathrm{Ce}_{2} \mathrm{O}_{3}$ & $\frac{14.54 \pm 3.17}{1.47-19.56}$ \\
\hline $\mathrm{MgO}$ & $\frac{0.04 \pm 0.03}{0-0.08}$ & $\mathrm{Pr}_{2} \mathrm{O}_{3}$ & $\frac{0.95 \pm 0.37}{0.13-2.05}$ \\
\hline $\mathrm{CaO}$ & $\frac{3.33 \pm 1.53}{0.34-17.84}$ & $\mathrm{Nd}_{2} \mathrm{O}_{3}$ & $\frac{3.22 \pm 1.02}{0.26-8.29}$ \\
\hline $\mathrm{MnO}$ & $\frac{0.21 \pm 0.38}{0-1.07}$ & $\mathrm{Sm}_{2} \mathrm{O}_{3}$ & $\frac{0.41 \pm 0.58}{0.14-2.61}$ \\
\hline $\mathrm{SrO}$ & $\frac{4.56 \pm 1.89}{0.33-14.11}$ & $\mathrm{Gd}_{2} \mathrm{O}_{3}$ & $\frac{0.17 \pm 0.14}{0-0.38}$ \\
\hline $\mathrm{BaO}$ & $\frac{0.55 \pm 1.02}{0-2.62}$ & $\mathrm{ThO}_{2}$ & $\frac{1.51 \pm 1.84}{0.25-12.87}$ \\
\hline $\mathrm{Na}_{2} \mathrm{O}$ & $\frac{8.06 \pm 1.8}{2.89-14.02}$ & & \\
\hline
\end{tabular}


На разрезах через Аллуайвский участок месторождения (рис. 3) общее содержание редкоземельных элементов в лопарите малиньитов незначительно возрастает с глубиной. На этом фоне проявлено несколько горизонтов лопарита с пониженным содержанием редкоземельных элементов, связанных, прежде всего, с линзами фоидолитов. Содержание $\mathrm{Nb}$ и Та ведёт себя обратно пропорционально таковому REE и Ti вследствие изоморфизма по основной для рассматриваемого комплекса (лопарит+перовскит)-луешитовой схеме $0.5 \mathrm{Na}^{+}+0.5 \mathrm{REE}^{3+}+\mathrm{Ca}^{2+}+2 \mathrm{Ti}^{4+} \leftrightarrow 2 \mathrm{Na}^{+}+2(\mathrm{Nb}, \mathrm{Ta})^{5+}$.

Таблица 2. Результаты факторного анализа данных о составе лопарита.

\begin{tabular}{|c|c|c|c|c|c|}
\hline Компонент & Фактор 1 & Фактор 2 & Компонент & Фактор 1 & Фактор 2 \\
\hline $\mathrm{SiO}_{2}$ & -0.280 & 0.050 & $\mathrm{Y}_{2} \mathrm{O}_{3}$ & 0.107 & 0.191 \\
\hline $\mathrm{TiO}_{2}$ & $\mathbf{0 . 7 9 0}$ & $\mathbf{- 0 . 5 4 6}$ & $\mathrm{La}_{2} \mathrm{O}_{3}$ & $\mathbf{0 . 5 9 9}$ & $\mathbf{0 . 5 7 9}$ \\
\hline $\mathrm{ZrO}_{2}$ & 0.144 & 0.220 & $\mathrm{Ce}_{2} \mathrm{O}_{3}$ & $\mathbf{0 . 8 6 3}$ & 0.399 \\
\hline $\mathrm{Fe}_{2} \mathrm{O}_{3}$ & -0.160 & -0.271 & $\mathrm{Pr}_{2} \mathrm{O}_{3}$ & $\mathbf{0 . 5 6 1}$ & 0.373 \\
\hline $\mathrm{CaO}$ & $\mathbf{0 . 4 3 3}$ & $\mathbf{- 0 . 6 4 6}$ & $\mathrm{Nd}_{2} \mathrm{O}_{3}$ & $\mathbf{0 . 8 4 1}$ & 0.006 \\
\hline $\mathrm{SrO}$ & 0.066 & -0.488 & $\mathrm{Sm}_{2} \mathrm{O}_{3}$ & 0.063 & -0.011 \\
\hline $\mathrm{Na}_{2} \mathrm{O}$ & -0.294 & $\mathbf{0 . 8 0 7}$ & $\mathrm{Gd}_{2} \mathrm{O}_{3}$ & 0.141 & 0.150 \\
\hline $\mathrm{K}_{2} \mathrm{O}$ & -0.065 & 0.089 & $\mathrm{ThO}_{2}$ & -0.303 & $\mathbf{- 0 . 5 5 8}$ \\
\hline
\end{tabular}
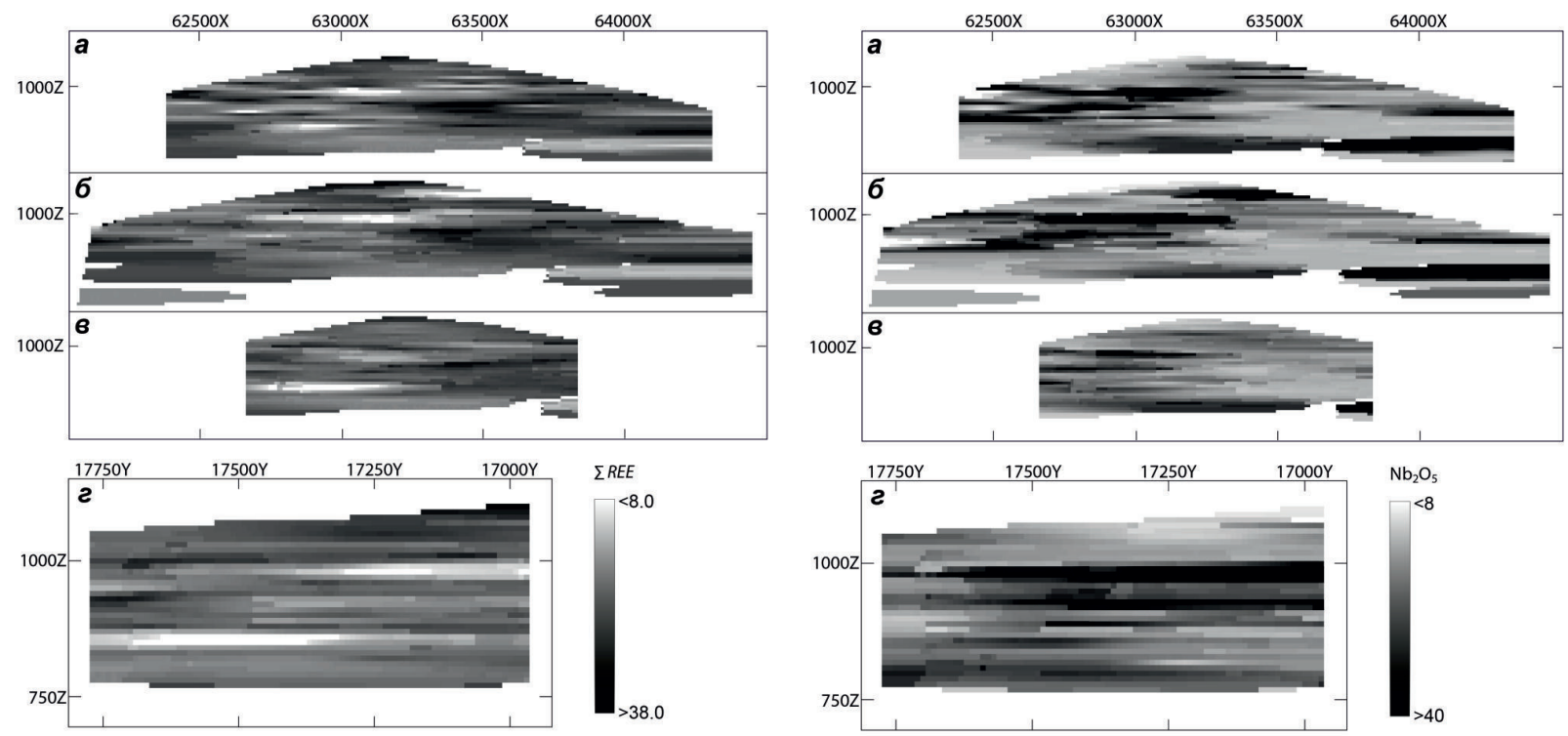

Рис. 3. Вариации содержания некоторых оксидов в лопарите:

$R E E_{2} \mathrm{O}_{3}$ - слева, $\mathrm{Nb}_{2} \mathrm{O}_{5}$ - справа (а, б, в - разрезы с запада на восток; $\Gamma$ - разрез с севера на юг).

\begin{tabular}{|l|l|l|l|l|l|}
\hline $\mathrm{Nb}_{2} \mathrm{O}_{5}$ & $\mathbf{- 0 . 9 1 6}$ & 0.284 & Вклад в дис- & 23 & 16 \\
\cline { 1 - 5 } $\mathrm{Ta}_{2} \mathrm{O}_{5}$ & -0.260 & -0.267 & персию, \% & 23 \\
\hline
\end{tabular}

Примечание: жирным шрифтом выделены факторные нагрузки, превышающие значение \pm 0.5 .

С учётом изменчивости состава эвдиалита (см. статью Малыгиной и др. в настоящем сборнике), можно заключить, что разработка комплексных Zr-REE-Ti-Nb-Ta руд месторождения должна опираться на детальную 3-мерную модель месторождения с целью оперативного управления процессом получения эвдиалитового и лопаритового концентратов определённого состава. Это, в свою очередь, требует построения геометаллургической модели эвдиалитового месторождения, учитывающей технологические требования соответствующих обогатительных и гидрометаллургических процессов. 
Работы проводились при финансовой поддержке Программы 48 Президиума РАН.

\section{Литература}

1. Буссен И.В., Сахаров А.С. Петрология Ловозерского щелочного массива. Л.: Наука, 1972. 296 c.

2. У Уткин М.Ю., Сухарев В.Н., Киричек О.П., Уткина Г.А., Лопатин А.С., Кононова Л.Н., Гордиенко А.В., Сайков С., Михаэлис Н.Г. Отчёт о предварительной разведке эвдиалит-лопаритовых и эвдиалитовых руд участка Аллуайв месторождения Чинглусуай в 1989-1992 гг. (книга 1). Ревда, 1995 г. 144 с.

3. Kalashnikov A.O., Konopleva N.G., Pakhomovsky Ya.A., Ivanyuk G.Yu. Rare Earth Deposits of the Murmansk Region, Russia-A Review // Economic Geology, 2016. V. 111. P. 1529-1559.

4. Korchak Yu.A., Men'shikov Yu.P., Pakhomovskii Ya.A., Yakovenchuk V.N., Ivanyuk G.Yu. Trap Formation of the Kola Peninsula // Petrology. 2011. V. 19. N. 1. P. 87-101.

5. Mikhailova, J.A., Kalashnikov, A.O., Sokharev, V.A., Pakhomovsky, Ya.A., Konopleva, N.G., Yakovenchuk, V.N., Bazai, A.V., Goryainov, P.M., Ivanyuk, G.Yu. 3D mineralogical mapping of the Kovdor phoscorite-carbonatite complex (Russia) // Mineralium Deposita. 2016. V. 51 (1). P. 131-149.

6. Mitchell R.H., Welch M.D., Chakhmouradian A.R., Mills S. Nomenclature of the perovskite supergroup: A hierarchical system of classification based on crystal structure and composition // Mineral. Mag. 2017. V. 81. P. 411-461.

7. Pakhomovsky Ya.A., Ivanyuk G.Yu., Yakovenchuk V.N. Loparite-(Ce) in rocks of the Lovozero layered complex at Mt. Karnasurt and Mt. Kedykvyrpakhk // Geology of Ore Deposits. 2014. V. 56. N. 8. P. 685-698. 